\title{
Research and Practice on the guarantee mechanism of excellent athletes' cultural teaching quality
}

\author{
Zhou Junlai ${ }^{1, a}$, Li Aichun ${ }^{2, b}$ \\ ${ }^{1}$ Hainan College of Sports, Hai Kou,570203, China \\ ${ }^{2}$ Hainan Normal University , Hai Kou,571158, China \\ ${ }^{a}$ zhoujunlai@zjut.edu.cn, ${ }^{b}$ Lac105@163.com
}

Keywords: elite athletes, culture teaching, guarantee mechanism, motivation

\begin{abstract}
Teaching quality is the core of the development of higher education and the lifeline of higher education. Teaching quality is not only the core competence of higher vocational colleges to long-term development, but also the key to realize sustainable development. For the higher vocational sports institute with competitive sports characteristics, the significance is more profound, the task is a heavy responsibility and a long road. In view of the cultural situation of elite athletes in higher vocational sports colleges, Since the school was founded, the college has been devoted to the exploration and practice of teaching quality, and has been constantly exploring, practicing and reflecting on the problems of "cultural learning crisis", such as students' weariness of learning and abandonment of learning, self-abdication and so on. From the perspective of the main elements of culture teaching, the motivation of athletes' students, the angle of teaching subject 、 the angle of systematic management and total quality management, it organically integrates the idea reform and the source encouragement. This paper constructs and practices a set of guarantee mechanism to encourage the quality of culture teaching of outstanding athletes in our college, such as process management and quality control, and so on.
\end{abstract}

\section{Introduction}

With the development of society, competitive sports is an important part of human social life and play a more and more important role, it have become the "window" of the comprehensive strength of the country and nation, such as politics, economy, culture, science and technology, etc. the development of competitive sports is not only the competition of physical ability and skill, but also the competition of Science and technology and intelligence. it is the competition of talents in the final analysis. It is the competition that the human quality promotes and challenges the human body limit in an all-round way. Athletes are the core strength of competitive sports talents. Their cultural and educational level will affect the improvement of competitive performance and the overall development of comprehensive quality, which is of great importance to the development of sports in China and the world. For a long time, the system of athletes' cultural education, which is run by the sports system, is divorced from the educational environment. Because the teaching thought, teaching content and teaching method deviate from sports team to some extent, the strategic 
position of education has not been fully implemented in practical work, and the mechanism of mutual promotion between culture education and sports training has not been formed. Athletes' awareness of cultural learning only exists in the superficial level of perceptual cognition. Because of the lack of internal driving force, athletes' cultural teaching has "cultural learning crisis" such as weariness of learning and abandonment of learning. For this reason, the result is: can not effectively scientific training, affect the promotion of competitive ability; re-employment difficulties after retirement; affect the construction of competitive reserve talents, affect the healthy and rapid development of competitive sports; lack of cultural quality, Finally, it will affect the competition of our country's comprehensive national strength.

At present, the relevant departments in charge of our country have paid general attention to the cultural teaching of excellent athletes, and have successively formulated a series of policies and regulations on the guarantee of athletes' right to culture and education, the guarantee of the quality of cultural teaching, and so on. It have gave strong support that the reform practice of grassroots organizations also, athletes re-employment after a lot of embarrassment seems to wake up. However, most of them are still passive because the concept of culture and education of outstanding athletes has not been really promoted, the leaders pay attention to and implement the wrong points, the contradiction between organization support and learning and training, the awakening of athletes themselves and the lack of internal motivation, and so on. Give up on yourself. Therefore, the relevant departments, experts and scholars have made a great deal of exploration and practice on the cultural teaching of athletes, but it is not difficult to find that these explorations and practices are mostly intended to improve the external educational environment of cultural teaching. While ignoring the fundamental and internal factor of determining the quality of athletes' cultural teaching, the motivation of subjective initiative is the internal relationship of top-down operation guarantee mechanism, such as top-level design, organizational support and participation of all members.

as a whole, On the basis of mastering the teaching information of athletes' culture, from subject angle of teaching, systematic management and total quality management, this paper organically integrates the subjective and relational elements of the guarantee of cultural teaching quality of outstanding athletes. The innovation and practice of encouraging and guaranteeing mechanism of culture teaching of elite athletes can arouse the enthusiasm of the main body of culture teaching of athletes, promote the comprehensive quality, promote the improvement of competitive level and enhance the competitiveness of employment. It is of great practical significance to promote the construction of competitive sports reserve talents.

\section{Content and effectiveness}

\subsection{From the Top level Design, build the Scientific View of Cultural Education and Teaching quality of Elite athletes}

It was carried the spirit of the "Circular on further strengthening of athletes' Cultural Education and guidance on ensuring athletes' work" (issued by the State Administration of China No. 23 / 2010), a special conference on safeguarding athletes' cultural learning was held. We have carefully studied the spirit of "guiding opinions", checked the arrangement of work against the "guiding opinions", unified point of view, established and improved the organizational system, guaranteed time and funds and facilities, and took the teaching and research offices as units. Organizing special seminars and special research for all staff many times, taking full staff participation, concept reform, source encouragement, operation management and quality control as the key points of implementation, adopting methods of field investigation, special research, etc. The investigation, interview and discussion of the teaching administrators, teachers, coaches, team leaders and 
students are carried out in an all-round way, and the present situation of the culture teaching of athletes and students is dynamically grasped, the current situation of encouragement, the real demand and psychological characteristics and the reasons are also discussed. Take targeted countermeasures and measures, and strictly implement.

At present, from the top level design, it is clear that the athletes' cultural teaching is a systematic project that requires the participation of the whole staff, and realizes the reform of athletes' students' desire for "gold medal" and neglects the cultural teaching to the "all-round quality" education idea. The personnel training measures of "grasping athletes' cultural teaching as grasping training" have improved the athletes' cultural education and highlighted the orientation and role of cultural education in the all-round development of athletes. Alleviates the leader's attention and the implementation of the wrong section and the long-lasting contradiction between learning and training.

\subsection{From the Power Source, constructed the Management system of the Elite athletes' Culture Teaching motivation}

\subsubsection{Credit incentive system}

Arouse students' enthusiasm and initiative enthusiasm of elite athletes in cultural learning, encourage elite athletes to train hard, to make outstanding achievements in international and domestic competitions, to win honor for the country, for the province, for the college, At the same time, in order to carry out the teaching management method of credit system in our college and train outstanding sports talents for the society, the study is based on the full field investigation and according to the characteristics of athletes' culture and education.It have been formulated that The measures on the Administration of Award credits for competitive Sports majors in XX Vocational Sports College of (try out), from the applicable objects of award credits, the scope of recognition of rewards credits, the recording and use of rewards credits, and the application time of rewards credits, The procedure is clearly defined and explained, which solves the dilemma of learning and training.

\subsubsection{Talent selection and incentive system}

It were established the leading group and working group of athletes' cultural education On the basis of the national enrollment policy, The leading group is composed of the education department, the sports bureau and the college to form a leading group for recruiting students. Those in charge are the heads of the units, The working group consists of the relevant leaders of the Department of Teaching and Student Management, the Department of physical Education, the affiliated Sports School and Coaches, The leading group is responsible for coordinating, directing, researching and solving major issues in athletes' cultural and educational work. The working group is responsible for the concrete implementation of the relevant requirements of the leading group, including comprehensive academic performance, sports performance, quality and potential, etc., in the selection of admission, the evaluation of scholarships, the selection of entries and the promotion of excellence in employment, etc., from . Various aspects such as the entrance process and export encourage teaching, which effectively realize multiple evaluation and healthy and orderly competition. 


\subsection{Hierarchical teaching incentive system}

\subsubsection{Athlete student stratification}

It is understand the students' learning motivation, attitude, mood, habits, self-concept, interpersonal relationship, history of study and sports achievement through observation and conversation, and to correct their homework through case analysis. Opolls and other forms of accurate examination of student personality differences, stratification of students, teaching according to their aptitude.

\subsubsection{Content design stratification}

It is goal of quality education according to the status, function, type and the specific, established the focus and main aspects of classroom teaching, analyzed on the basis of the nature and characteristics of teaching content, determines the concept and proposition of the course. The time ratio of solving the problem and the different emphasis on the corresponding three quality requirements. According to the students' reality, from the requirements of different levels of "understanding, mastering, applying and innovating", this determines the specific teaching objectives of each class, focuses on the whole, links in layers, and pays attention to the coherence and coordination of knowledge. Focusing on the whole teaching material and combining with the concrete situation of the students, the author formulates the overall goal of stratification, then distributes it to every unit, and then distributes it to each class, which not only lightens the burden of study, but also highlights the teaching according to students' aptitude.

\subsubsection{Evaluation stratification}

We should find out the deficiency in teaching in time, timely feedback, strengthen in time, correct in time, attach importance to the degree of effort and progress in the process of students' study. Carrying out the formative gradient test. The test questions are designed to be stratified or assessed separately at each level to determine the credit, and to evaluate the students' achievement by a certain proportion, which takes into account the exemplary role of the A-level students. Strengthen the management of $\mathrm{C}$ level students, mobilize the learning enthusiasm of $\mathrm{B}$ level students.

\subsection{Perfecting the running management system of culture Teaching of elite athletes from the aspect of operation management}

\subsubsection{Leadership responsibility system:}

A leading group headed by major leaders and a working group that is composed of relevant education and teaching departments, it have been stetted up to form the main leadership of the college, the teaching department to take the lead, the training and competition departments to cooperate, the teaching units to carry out the specific efforts, and The work pattern of joint operation and joint management.

\subsubsection{System of thematic research activities:}

Strengthened the special research on athletes' culture and education, to improved the theoretical level and practical application ability of athletes' culture and education, and to perfect the training plan, teaching plan and curriculum for competitive sports professionals. To promote the preparation 
of school-based textbooks and course assignments (exercises) and so on.

\subsubsection{The team leader entered the classroom system}

The office is equipped with personnel that responsible mastered the cultural education of athletes, the team leader is required to attend class not less than 2 times a month, to understand the cultural learning situation of the team's athletes and students;

\subsubsection{Class teachers (class teachers) in the team system}

Require the head teacher (teacher) to go deep into the sports team at (the) least twice a month, and timely understand and feedback the education and teaching of athletes;

\subsubsection{Regular statistics and feedback system for class and academic achievement.}

Daily follow-up, analysis of athletes' cultural learning information, weekly feedback to the teaching departments and sports departments;

\subsubsection{The regular meeting system of athletes' cultural education and teaching work.}

Communicate with each other quarterly, feedback, regular meeting to exchange information and report the results of the evaluation process;

\subsubsection{The three term system.}

It is breaked the system of winter and summer vacation in ordinary schools According to the characteristics of athletes, arranged cultural study and vacation time according to the rules of training and competition. It is necessary to improve the teaching reform scheme of "three-term system". The time of the third term (summer term) is generally five weeks. The emphasis is placed on arranging humanistic quality courses to improve the humanistic literacy of athletes' students, and combining with "online classroom". Ensure the teaching quality of the three-term system.

\subsection{Perfected the monitoring and evaluation system of cultural teaching quality guarantee for elite athletes from the aspect of quality supervision,}

It is founded college academic committee, a teaching steering committee and a competitive professional construction steering committee with the participation of enterprise, industry and technical experts and management personnel, that were set up to strengthen the organization, construction and macro management of the teaching quality of the school. At the same time, we have established the system of feedback of teaching information, the system of teaching supervision, the system of teaching inspection at the beginning, the middle and the end of the term, The system of investigation and research on special teaching of elite athletes in cultural learning, the system of special teaching and research reports, the system of graduate tracking and investigation, and the system of monitoring and controlling the culture and education of outstanding athletes and the evaluation system of teaching quality. That was monitored the quality of teaching input from the aspects of school running thought, major setting, curriculum setting, management system, monitoring and evaluating system for teachers, monitoring and evaluating system for students, conditions for running a school, and so on. In practice teaching, teaching outline, teaching plan, grade assessment and so on, the quality of teaching operation is strictly supervised, and the quality of teaching output is seriously evaluated from many aspects, such as introducing market and social 
evaluation mechanism and introducing social evaluation, etc. And the culture teaching work will be included in the performance appraisal of the relevant staff members, adhere to the daily tracking, weekly feedback, monthly assessment, quarterly summary, the first half year evaluation, the work assessment mechanism of the year-end general evaluation, and so on.

At present, the application has achieved remarkable results, which solves the mainly problem of the educational concept of athletes' students, they wish to save "gold medals" and neglects cultural teaching, and effectively alleviates the weariness of learning and abandoning school because of the lack of internal driving. "Learning crisis" such as self-abdication: the attendance rate is rising athletes' cultural learning day by day, the weekly attendance rate is nearly 100 , the average attendance rate of the period is 93.89, the enthusiasm of learning is improved significantly, the attitude of learning is obviously improved, the examination is serious and the passing rate is significantly improved. The college is realized gradually the effective leadership, the organization supported and the entire staff participation multi-direction and multi-channel joint management elite student culture teaching good situation.

\section{Conclusions}

The cultural education of athletes what is related to the sustainable development of the country and competitive sports, so it is necessary to carry out the spirit of "guiding opinions", to grasp the spirit of national athletes' cultural education and ensured teleconference sprit.. refines and details, break through the difficulties, innovate and develop, perfect the guarantee; that is consolidated the environmental foundation of the combination of competition and education, established and improved the entrance competition mechanism, the process incentive management mechanism, the multiple evaluation of the export mechanism, Good entrance, process and export quality three levels; organic integration of concept reformed, source incentive, operation management, It achieved effective leadership of quality controlling, organization support and participation of all staff ,It ensured the quality of cultural education and teaching athletes, Improved athletes' cultural quality. That is contribute to the construction of strong sports provinces and sports powers.

\section{References}

[1] Liu yan Tao.Research on Cultural Education Statusand Strategy of Athletes from Affiliated SportSchool of Beijing Sport University[D], Beijing Sport University,2017.5

[2] ZOU Guo-Zhong, CHEN Shao-Cheng.Research on Current Situation of the Top Athletes.Education and Optim ization about Security System of Ath-letes.Education[J], Journal of Nanjing Institute of PhysicalEducation,2010;24(3):95-99

[3] DINGHa-i yong,HAN Dong,SHAO Bin,MUGuo-hua..Research on the Status Quo and Countermeasures of Chinese Elite College Athletes Contradiction between Academic Study and Training Journal of Beijing Sport University.2007;30(3)374-376

[4] GAO Hang. Teaching Mode Construction of Excellent Athletes in China[J]. Journal of Jilin Sport University,2017;33(6)49-51

[5] Analysis on the lack of Culture and Education of Elite athletes in China[J]. Sports Culture Guide,2016;2:71-76

[6] Li Cheng Feng.The Research on Policies and Practice for Chinese Elite Players Education[D].Beijing Sport University,2011.6

[7] Zhao YanYan.The lack of Cultural Education of athletes and the way of Reform in the View of Human's All-round Development [J].Contemporary Sports Technology,2017; 34 (7)182 